\title{
Extending the perspective on left ventricular assist device pump thrombosis to left ventricular assist device system thrombosis
}

\author{
Robert L. Kormos, MD
}

\footnotetext{
From the Department of Cardiothoracic Surgery, Presbyterian University Hospital, University of Pittsburgh, Pittsburgh, Pa.

Disclosures: Author has nothing to disclose with regard to commercial support.

Received for publication Sept 1, 2017; accepted for publication Sept 8, 2017; available ahead of print Oct 15 , 2017.

Address for reprints: Robert T. Kormos, MD, Department of Cardiothoracic Surgery, Presbyterian University Hospital, University of Pittsburgh, 200 Lothrop St, Suite C-800, Pittsburgh, PA 15213 (E-mail: kormosrl@ upmc.edu).

J Thorac Cardiovasc Surg 2018;155:e37-8

$0022-5223 / \$ 36.00$

Copyright $(C) 2017$ by The American Association for Thoracic Surgery

https://doi.org/10.1016/j.jtcvs.2017.09.079
}

The ability to return to a normal lifestyle with minimal malfunctions after having a left ventricular assist device (LVAD) implanted is based on the reliability of the pump and its components. It is an important part of improved quality of life.

The incidence of pump thrombosis in durable rotary LVADs varies between $7 \%$ and $14 \%$, depending on the type of rotary pump and the era of implantation. ${ }^{1}$ This problem relates to hemocompatibility, and risk factors include a combination of patient characteristics, engineering design factors of the pumping components, and procedural or management issues. ${ }^{2}$ The HeartMate 3 (Thoratec Corporation, Pleasanton, Calif) uses engineering solutions that have obviated reports of pump thrombosis seen in other rotary pumps. ${ }^{3}$ In all clinical trials with LVADs and in recent reports with large registries (INTERMACS), the definition of pump thrombosis is based on biochemical testing that reflects elevated lactate dehydrogenase or plasma free hemoglobin, along with power and flow profiles that suggest increased resistance to rotor operation. ${ }^{4}$ These reports focus on pump thrombosis that is specific to the internal rotary mechanism and does not delineate a subset of thrombosis that is specific to the pump inflow or outflow cannulas or grafts. This information has not been collected in a granular fashion and if these latter components were included, it is not known what the global rates of LVAD system thrombosis would be for any LVAD.

The report in this issue of the Journal by Grüger and colleagues ${ }^{5}$ from the German Heart Center describes thrombosis of the outflow graft of the HeartMate 3 that appears to have occurred as a result of spontaneous torsion of the graft more than 2 years after implantation making surgical implantation technique an unlikely cause. They hypothesize that the rotated graft, which was corrected by turning the graft back to a normal alignment, could have spontaneously rotated in the patient with time. Another possibility is that

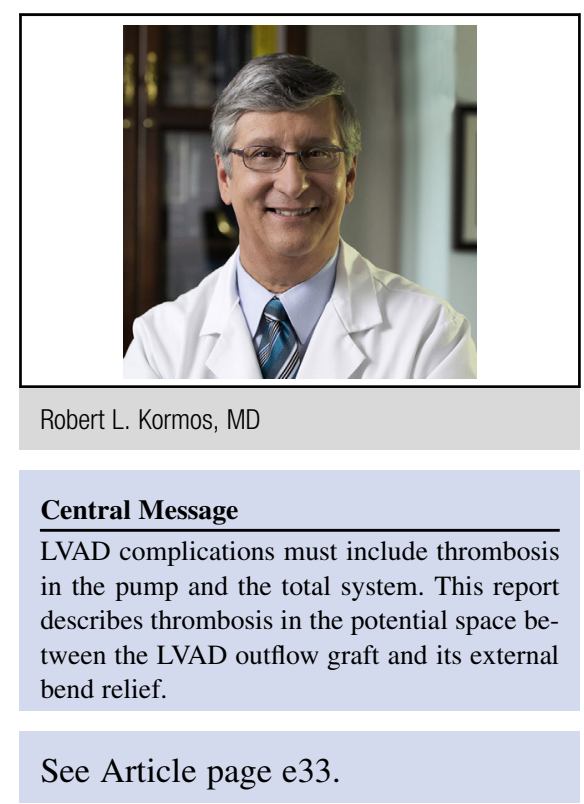

twisting of the graft during implantation, which was distributed along the length of the graft, could have localized over a focal length during the 2 years after implantation. A very similar complication, including the same direction of graft rotation, was diagnosed in a second patient 20 months after HeartMate 3 implantation and treated in the same way with a minimally invasive technique.

Grüger and colleagues ${ }^{5}$ sewed the graft to the ascending aorta before attaching it to the LVAD connector. If the graft is first attached to the LVAD, then appropriate alignment with the aorta, and the estimation of appropriate graft length may be more reliably made. Given the late presentation of these events, however, surgical technique may not be the issue.

A report of outflow graft obstruction occurred during the CE Mark trial with the HeartMate 3, but the underlying mechanism was unclear. Another report of 2 cases of outflow graft occlusion in the HeartMate 3, from Duero Posada and colleagues ${ }^{6}$ at the Toronto General Hospital, describes outflow graft occlusion secondary to the collection of thrombotic material between the graft and the bend relief. As in this report of Grüger and colleagues, ${ }^{5}$ those cases occurred late after surgery, at 6 months and at 1 year. ${ }^{6}$ Duero Posada and colleagues ${ }^{6}$ hypothesize that transudate or blood leaking into the virtual space between the outflow graft and the bend relief resulted in lumen occlusion. The 
bend relief in the HeartMate II is of a similar configuration as the HeartMate 3, and 2 reports exist of such outflow graft occlusion seen within the bend relief segment of the HeartMate II outflow graft, with delayed compromise of flow at 2 and 2.5 years after implantation. ${ }^{7,8}$ In these cases, the obstruction was resolved with an intravascular stent. Indeed, there are reports of outflow graft occlusion occurring secondary to graft compression with thrombus trapped under polytetrafluoroethylene wrapping used to reduce adhesions during the subsequent heart transplant.

This case report of Grüger and colleagues ${ }^{5}$ emphasizes the importance of detailed documentation of adverse events regarding modes of LVAD malfunction. These events may not be reported in clinical trials, because they occur beyond the initial study follow-up period, nor are they clearly incorporated into existing registries, such as INTERMACS. LVAD surgery is characterized by major interinstitutional variability; this was discovered in the HeartMate II postmarket experience in relation to pump thrombosis but is not exclusive to that manufacturer. ${ }^{9}$ How these variations in technique effect such events is again poorly documented. The design of data collection in postmarket registries is critical to the understanding of long-term success or failure with these devices. Knowledge of whether this complication is a result of variable surgical technique, inherent physiologic reactions of patients, or a lack of robustness of design of the technology can only come from a deep examination and root cause analysis of evidence obtained from carefully collected real-world data.

\section{References}

1. Kirklin JK, Naftel DC, Pagani FD, Kormos RL, Myers S, Acker MA, et al. Pump thrombosis in the Thoratec HeartMate II device: an update analysis of the INTERMACS Registry. J Heart Lung Transplant. 2015;34:1515-26.

2. Mehra MR. The burden of haemocompatibility with left ventricular assist systems: a complex weave. Eur Heart J. February 23, 2017 [Epub ahead of print].

3. Mehra MR, Naka Y, Uriel N, Goldstein DJ, Cleveland JC Jr, Colombo PC, et al; MOMENTUM 3 Investigators. A fully magnetically levitated circulatory pump for advanced heart failure. N Engl J Med. 2017;376:440-50.

4. Blitz A. Pump thrombosis-A riddle wrapped in a mystery inside an enigma. Ann Cardiothorac Surg. 2014;3:450-71.

5. Grüger T, Kaufmann F, Dreysse S, Falk V, Krabatsch T, Potapov E. Late post-pump blood flow obstruction in a novel left ventricular assist device: the unusual case of a twisted outflow graft. J Thorac Cardiovasc Surg. 2018; 155:e33-5.

6. Duero Posada JG, Moayedi Y, Alhussein M, Rodger M, Alvarez J, Wintersperger BJ, et al. Outflow graft occlusion of the HeartMate 3 Left Ventricular Assist Device. Circ Heart Fail. 2017;10.

7. Hubbert L, Forssell C, Baranowski JK, Lindgren B, Holm J, Ahn H. Endovascular stenting of a LVAD outflow graft thrombosis. ASAIO J. 2017;63:e3-5.

8. Abraham J, Remick JD, Caulfield T, Puhlman M, Evenson K, Ott G, et al. Left ventricular assist device outflow cannula obstruction treated with percutaneous endovascular stenting. Circ Heart Fail. 2015;8:229-30.

9. Maltais S, Kilic A, Nathan S, Keebler M, Emani S, Ransom J, et al. PREVENtion of HeartMate II Pump Thrombosis Through Clinical Management: the PREVENT multicenter study. J Heart Lung Transplant. 2017;36:1-12. 